\title{
RENAL AND VASCULAR DISTURBANCES IN A CASE OF THALLIUM POISONING
}

BY

\author{
S. T. WINTER, Z. LARON and I. C. MICHAELSON \\ From Rambam Government Hospital, Haifa, Israel
}

(RECEIVED FOR PUBliCATION MAY 5, 1954)

The following case report of thallium poisoning is of interest from several points of view. It emphasizes the effect of thallium on the renal and vascular systems and its role as a possible cause of hypertension even in childhood; it indicates that a complete cure may be obtained without the use of dimercaprol (B.A.L.); and it affords scope for discussion of the possible mechanisms whereby, in thallium poisoning, changes are produced in the kidneys and blood vessels.

\section{Case Report}

N.S., a 9-year-old Yemenite Jewish boy, five years in Israel, was admitted on May 2, 1953, from a boarding school because of slight neck stiffness. One week before admission the child had begun to limp and his behaviour became strange. Two days before admission he had complained of pains in the left leg, and on the following day he had refused to eat, vomited, lay curled up in bed, and had shown no interest in his surroundings. The temperature had been normal.

On admission to the Rambam Hospital the patient gave the impression of being seriously ill. He weighed $20.5 \mathrm{~kg}$. and his temperature was $37^{\circ} \mathrm{C}$. His build was slim and the nutritional state was only fair. He was apathetic, lay in bed with his body in flexion, and consciousnesswas clouded. The pulse was 104 and regular. The liver edge was palpable just below the costal margin. Slight neck stiffness was present. He held the left lower limb in a state of flexion, and the left thigh was tender to pressure. The plantar response on the left side was indefinite but occasionally extensor. The tendon reflexes were present and his gait was unsteady, almost waddling.

Lumbar puncture on admission yielded a clear fluid, not under pressure, and the cerebrospinal fluid showed an absence of cells and a negative Pandy reaction. Ophthalmoscopic examination of the fundi showed the discs to be normal. They remained so throughout subsequent examinations. Slit lamp examination of the anterior eye revealed no abnormality.

The child remained in this apathetic state for a number of days, was uncooperative, refused food and appeared very depressed. At night he complained of pain in the muscles of the left thigh. His gait remained unsteady, and there was a marked lumbar lordosis with prominence of the abdomen. On May 10 it was first noticed that the hairs of the scalp began to fall out in large amounts, the eyebrows remaining comparatively unaffected. The skin of the extensor surfaces of both hands showed a scaly, cracked and roughened appearance. The gums were red and swollen and they bled easily. On the following day similar skin changes were noticed over the ankles and on the forehead.

On May 11 there was a noticeable improvement in the child's general condition. He became cooperative and was much happier. About this time the possibility of thallium poisoning was considered. A detailed enquiry into the child's previous history revealed that he had always been well, happy and sociable. We learnt that thallium-coated wheat grain was used as a rat poison at the school, although special precautions were taken to prevent children having access to it. Furthermore, the child at first denied having eaten any such grain, though he later admitted to tasting it. Spectroscopic examination of the urine on May 15 revealed appreciable amounts of thallium, thus confirming absolutely the diagnosis of thallium poisoning. Spectroscopic examination of the blood on May 18 was negative for thallium.

On May 13 the blood pressure was first recorded and was found to be $170 / 145 \mathrm{~mm}$. $\mathrm{Hg}$, although the child's sole complaint was occasional pain in the left thigh. On the following day the blood pressure rose to $180 / 165 \mathrm{~mm} . \mathrm{Hg}$, and a second lumbar puncture yielded clear fluid under a pressure of $160 \mathrm{~mm}$. water. The Queckenstedt test was positive, and cell and biochemical findings were normal. On May 15 the child suffered from two attacks of convulsions, separated by an interval of three hours. In the first attack he lost consciousness, maintained the left upper and lower limbs in flexion, and the limbs on the right side in extension. This was followed by clonic spasms, particularly on the left side. He became pale but did not foam at the mouth or pass urine. The convulsion passed after about two minutes, and the child immediately appeared to regain full consciousness. The second fit was accompanied by a short cry, and affected both sides of the body although more the left side. There were numerous small movements of the fingers of the left hand, but the child rapidly regained consciousness after the convulsion. 
His general condition remained quite good, and he showed normal interest in his surroundings. The skin changes became progressively less marked. A detailed neurological examination showed sensation to light touch to be normal and the left plantar response to be extensor.

The blood pressure remained in the neighbourhood of $185 / 150 \mathrm{~mm}$. Hg. Although the child did not show polydipsia, the specific gravity of the urine was 1,010 or less. The urine concentration and urea clearance tests showed definitely pathological values, as described below and shown on Fig. 1.

On May 24 he had a further attack of convulsions, which affected mainly the left side of the body and which passed without sequelae after five minutes. During the three days following this third fit the systolic blood pressure reached $200 \mathrm{~mm}$. Hg. Frequent blood pressure measurements during the subsequent three weeks showed raised values with slight variations, but never falling below $140 / 100 \mathrm{~mm}$. $\mathrm{Hg}$ with the patient in a recumbent position.

On May 28 a strict rice and fruit diet was instituted for 22 days. As there was no marked fall in blood pressure during this regime, trials with hexamethonium bromide were begun and the patient received three injections of this drug. Details of the response are given in the table. No B.A.L. was administered. About June 16 the blood pressure began to show a gradual but marked fall, and by June 20 a value of $115 / 75 \mathrm{~mm}$. $\mathrm{Hg}$ was recorded. Accordingly the trial with hexamethonium bromide was not continued. The blood pressure did not tend to rise again and on July 11 it reached a constant value of $106 / 65 \mathrm{~mm}$. $\mathrm{Hg}$.
There was a steady improvement in the general condition, and the skin gradually returned to a normal state. From June 24 it was noticed that the scalp hair had begun to grow again. The inflammation of the gums regressed and the gingival mucosa regained a normal appearance.

The child early became alert and happy, had a good appetite and appeared well, both physically and mentally, even during the period of hypertension. The temperature never rose above $37.5^{\circ} \mathrm{C}$. There was a steady improvement in the results of the urine concentration and urea clearance tests, which closely paralleled the return of the blood pressure to normal. These two tests of renal function were normal on discharge... On leaving the hospital on July 16,1953 , his general state was very good, and he had gained $500 \mathrm{~g}$. in weight during his in-patient stay.

On June 15 there was a marked narrowing of practically all the retinal arteries, the arterio-venous ratio in many places being 1 to 3 instead of the usual 2 to 3 . No haemorrhages or exudates were present. The disc, as already noted, was normal. The left fundus showed a similar appearance. It is not possible to state when the arteries became narrowed. This abnormal narrowing of the retinal arteries remained, although in a slightly less marked degree until the last fundal examination, which took place on October 4, 1953. On that date, in addition to the narrowing of the arteries, an increase in the central light streak of the arteries was noted. The latter fact and the continued narrowing of the arteries suggest that what may have been a functional condition had now been followed by organic changes. The visual acuities and visual fields were normal.

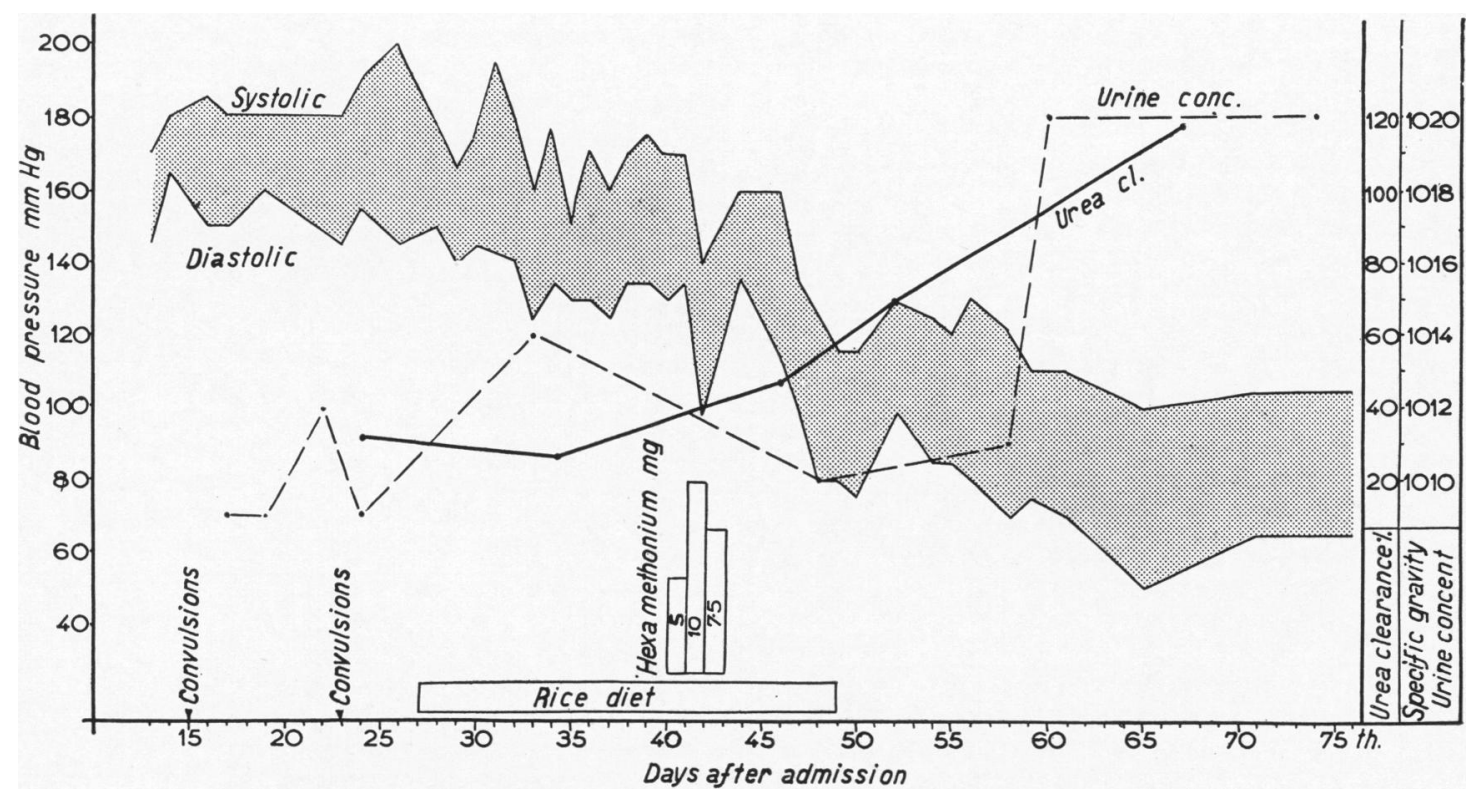

FIG. 1.-Correlation between blood-pressure changes and the results of kidney function tests, showing also the onset of convulsions and therapeutic measures. 
INVESTIGATIONS. Laboratory investigations gave the following results:

Urine. May 3, albumin 0.5 0/00; May 6, trace of albumin leucocytes 1-3; cylindroids; May 12, no abnormal constituents; May 25 and June 1, trace of albumin; June 10 and further examinations, no abnormal constituents.

Urine Concentration Tests (Specific Gravity). May 18, 1009; May 23, 1012; May 25, 1009; June 3, 1014; June 18, 1010; June 28, 1011; June 30, 1016; July 5, 1020; three further examinations, 1020.

Urea Clearance Tests. These are expressed as a percentage of clearance for two hourly specimens. May 25, I: $\max$. cl. 32\%, II: $\max$. cl. 30\%; June 4, I: $\max$. cl. $27 \%$, II: stand. cl. $25 \%$; June 16 , I: $\max$. cl. 47\%; II: $\max$. cl. 45\%; June 22, I:max. cl. 70\%; II: max. cl. 74\%; June 29, II: stand. cl. 90\%; July 7, I: $\max$. cl. $118 \%$, II: $\max$. cl. $100 \%$.

Blood Urea. Values between 16 and $25 \mathrm{mg}$. per $100 \mathrm{ml}$. were found.

TABLE

EFFECT OF SUBCUTANEOUS INJECTIONS OF HEXAMETHONIUM BROMIDE ON BLOOD PRESSURE

\begin{tabular}{|c|c|c|c|}
\hline & \multicolumn{3}{|c|}{ Blood Pressure (mm. Hg) } \\
\hline & Recumbent & Sitting & Standing \\
\hline 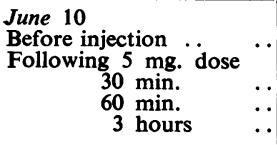 & $\begin{array}{l}170 / 130 \\
150 / 125 \\
130 / 115 \\
170 / 130\end{array}$ & $\begin{array}{l}130 / 110 \\
130 / 110 \\
160 / 130\end{array}$ & $\begin{array}{l}100 / 80 \\
120 / 105 \\
145 / 125\end{array}$ \\
\hline $\begin{array}{l}\text { June } 11 \\
\text { Before injection } \\
\text { Following } 10 \mathrm{mg} . \text { dose } \\
\begin{array}{l}30 \mathrm{~min} . \\
60 \mathrm{~min} .\end{array} \\
3 \text { hours }\end{array}$ & $\begin{array}{c}170 / 135 \\
90 / 0 \\
108 / 80 \\
128 / 100\end{array}$ & $\begin{array}{l}170 / 140 \\
85 / 0 \\
120 / 100\end{array}$ & $130 / 110$ \\
\hline $\begin{array}{l}\text { June } 12 \\
\text { Before injection ... } \\
\text { Following } 7 \frac{1}{2} \text { mg. dose } \\
\begin{array}{l}30 \text { min. } \\
60 \text { min. } \\
3 \text { hours }\end{array}\end{array}$ & $\begin{array}{l}140 / 100 \\
105 / 80 \\
110 / 85 \\
130 / 80\end{array}$ & $\begin{array}{l}145 / 100 \\
100 / 80 \\
120 / 100\end{array}$ & $105 / 70$ \\
\hline
\end{tabular}

Blood. Total proteins, $7 \cdot 6 \mathrm{~g}$. per $100 \mathrm{ml}$. (albumin 4.3/globulin 3.3); Weltman, 7; Takata Ara test negative; syphilis flocculation reaction negative; bilirubin test negative; cholesterol, $190 \mathrm{mg}$. \%; alkaline phosphatase, 2.4 B.U. \%; sugar, $88 \mathrm{mg}$. \%; $\mathrm{NaCl}, 615 \mathrm{mg}$. \%; potassium, $14 \mathrm{mg}$. \%; phosphorus, $4 \mathrm{mg}$. \%; prothrombin time, $100 \%$; B.S.R. (Westergren), 35/65 on May 2, 28/53 on July 8.

Blood Counts. May 2, Hb. 13.5 g. per $100 \mathrm{ml}$; R.B.C., $4.5 \mathrm{~m}$. per c.mm.; W.B.C., 4,300 per c.mm. (polymorphs $23 \%$, basophil 1\%, lymphocytes $73 \%$, monocytes 4\%); July 8, Hb. 10.4 g. per 100 ml.; R.B.C., 3m. per c.mm.; W.B.C., 5,000 per c.mm. (polymorphs $23 \%$, basophil $1 \%$, eosinophils $4 \%$, lymphocytes $69 \%$, monocytes 3\%).

Radiographs. The chest, skull and left femur were normal. An electrocardiogram was within normal limits. The injection of $5 \mathrm{mg}$. benzodioxane on May 21 was not followed by a fall in blood pressure.

\section{Discussion}

This patient presented the usual features of acute thallium poisoning, e.g. alopecia, skin changes, gingivitis, behaviour changes, convulsions and polyneuritic pains. The diagnosis was confirmed by finding thallium on spectroscopic examination of the urine.

A raised blood pressure is a recognized finding in acute thallium intoxication (Munch, Ginsburg and Nixon, 1933; Mazzei and Schaposnik, 1949; Meyler, 1952; von Oettingen, 1952), although the literature pays scant attention to its possible aetiology. The paucity of studies on the causation of hypertension in thallium poisoning compels us to attempt to compare thallium intoxication with that due to lead, another heavy metal, with regard to blood pressure and renal disturbances.

Both Fishberg (1934) and Cantarow and Trumper (1944) have discussed fully the problem of early hypertension in lead poisoning. They conclude, on the basis of surveys of clinical experiences and experimental studies on animals, that this 'early' rise in blood pressure is definitely not of renal origin, but is due to the direct action of lead in causing contracture of the smooth muscle of the small blood vessels including capillaries. It is probable that the retinal vascular changes, as well as the transient nature of the hypertension in our case, is supportive evidence of a similar mechanism, i.e. peripheral arterioconstriction, being the cause of a raised blood pressure in thallium poisoning.

The transient nature of the hypertension indicates that the general vascular changes were functional in origin, while the continued narrowing of the retinal arteries suggests in one tissue at least that this functional disturbance may be followed by organic change.

The possibility of the hypertension being secondary to changes in the kidney is difficult to accept in our case, as hypertension secondary to acute kidney disease usually accompanies glomerulonephritis (Wright, 1952). Our patient did not show the picture of acute nephritis.

Another possible mechanism for the hypertension might be damage to the medullary vasomotor centre, a suggestion based on the necropsy findings of 'profound extensive changes' with nerve cell degeneration at the base of the brain, as well as on symptoms related to the nervous system (Munch et al., 1933; Schild and Schrader, 1952). No signs of bulbar involvement were seen in our patient to confirm the possibility of damage to the vasomotor centre.

In considering whether the convulsions were due to metal poisoning of the cortical nerve cells or to 
vasoconstriction alone, the fact that the convulsions in our case were limited to three short fits only, despite a prolonged period of hypertension, and the absence of papilloedema, are against a hypertensive origin of the fits.

Clinical reports on thallium poisoning show a high percentage of patients with urinary findings of albumin, red and white cells, and casts (Gleich, 1931; Ginsburg and Nixon, 1932; Munch, 1934; Kallner, 1946; Diengott, 1951; Grulee and Clark, 1951). Post-mortem examinations of the kidneys after thallium intoxication have shown marked hyperaemia, cloudy swelling and degenerative changes in the cells of the glomeruli and tubules (Lynch and Scovell, 1930; Rambar, 1932; Munch et al., 1933).

The problem postulated by our case is whether the renal dysfunction was mainly the result of vascular spasm in the kidney, of direct toxic damage to the kidney cells, or of a combination of both factors. Albumin and cells in the patient's urine suggested glomerular damage, the reduced concentrating power of the kidneys suggested tubular dysfunction, and the clearance tests suggested damage to both glomeruli and tubules. The reversibility of the renal dysfunction, as judged by the various tests performed, indicated that the damage to the kidneys was not severe. There was a direct correlation between the fall in blood pressure and the recovery of normal kidney function, illustrated in Fig. 1. These clinical and laboratory findings suggest that the major factor in producing the renal dysfunction was the transient vasoconstriction within the kidney.

Hexamethonium bromide caused a marked depression of the blood pressure, the degree of the fall depending on the dose used. This fall in blood pressure in our patient offers no indication as to the cause of the hypertension in thallium poisoning, as the action of hexamethonium bromide on blood pressure is independent of the aetiology of the hypertension, whether renal or peripheral in origin (Lyons and Love, 1952). In our case the symptoms attributable to the raised blood pressure were indefinite. There is probably no indication to use this drug regularly unless the clinical picture shows severe manifestations of hypertensive origin. However, its use must be considered in cases of thallium poisoning, and a decision made on the individual patient.

A rice diet was given for 22 days, and during this time there was a slow downward trend in the blood pressure readings. However, one cannot conclude that this fall was due definitely to the effect of the diet alone, since the possibility of gradual detoxica- tion by excretion of the metal cannot be excluded.

Experimental work on the use of B.A.L. in induced poisoning in animals has shown no clear benefit from the drug in this condition (Longcope and Luetscher, 1949). Although some authors have claimed good results from B.A.L. therapy in thallium poisoning (Mazzei and Schaposnik, 1949; Welty and Berrey, 1950; Diengott, 1951; Schild and Schrader, 1952), their reports cannot be judged as convincing evidence, particularly as improvement in this complex clinical picture is not easy to assess. Previous experiences in this hospital with three children after thallium poisoning treated with B.A.L. were not convincing of its value. For these reasons B.A.L. therapy was deferred, and the child in the meantime showed a spontaneous improvement leading to complete recovery without this drug. These experiences have left us unconvinced of the value of B.A.L. in thallium poisoning. It is noteworthy that the general opinion (Longcope and Luetscher, 1949) is that B.A.L. is not effective in lead poisoning.

\section{Summary}

A boy aged 9 years, suffering from thallium poisoning, showed marked hypertension, renal dysfunction and retinal vasoconstriction, as well as the more usual clinical features of this intoxication.

All the manifestations, with the exception of retinal vascular constriction, cleared without the use of B.A.L. (dimercaprol). Trial doses of hexamethonium bromide produced a marked temporary fall of the blood pressure.

The aetiology of the hypertension and renal damage is discussed, and the analogy with lead poisoning is drawn. It is considered likely that the thallium brings about hypertension by a direct action on the blood vessels.

We wish to thank Dr. W. Falk and Dr. N. Herz for their great interest and assistance. Dr. O. Schnapp, of the Israel Institute of Technology, kindly performed the spectroscopic examinations.

\section{REFERENCES}

Cantarow, A. and Trumper, M. (1944). Lead Poisoning. Baltimore. Diengott, D. (1951). Acta med. orient., Tel-Aviv., 10, 17.

Fishberg, A. M. (1934). Hypertension and Nephritis, 3rd ed. Philadelphia.

Ginsburg, H. M. and Nixon, C. E. (1932). J. Amer. med. Ass., 98, 1076.

Gleich, M. (1931). Ibid., 97, 851.

Grulee, C. G. and Clark, E. H. (1951). Amer. J. Dis. Child., 81, 47. Kallner, A. (1946). Ann. paediat., Basel, 167, 188.

Longcope, W. T. and Luetscher, J. A. (1949). Advanc. intern. Med., 3, 39.

Lynch, G. R. and Scovell, J. M. S. (1930). Lancet, 2, 1340.

Lyons, R. H. and Love, V. L. (1952). Advanc. intern. Med., 5, 303. Mazzei, E. S. and Schaposnik, F. (1949). Brit. med. J., 2, 791 .

Meyler, L. (1952). Side Effects of Drugs, p. 84 . Amsterdam.

Munch, J. C. (1934). J. Amer. med. Ass., 102, 1929.

, Ginsburg, H. M. and Nixon, C. E. (1933). Ibid., 100, 1315 Oettingen W. F. von. (1952). Poisoning, p. 484. New York.

Rambar, A. C. (1932). J. Amer. med. Ass., 98, 1372.

Schild, W. and Schrader, A. (1952). Nervenarzt, 23, 288.

Welty, J. A. and Berrey, B. H. (1950). J. Pediat., 37, 756.

Wright, S. (1952). Applied Physiology, 9th ed., p. 357 . London. 